\title{
"We Are Only as Strong as We Are United, as Weak as We Are Divided" a Dynamic Analysis of the Peer Support Networks in the Harry Potter Books*
}

\author{
Goele Bossaert ${ }^{1}$, Nadine Meidert $^{2}$ \\ ${ }^{1}$ Research Unit Parenting \& Special Education, KU Leuven, Leuven, Belgium \\ ${ }^{2}$ Political Methodology, University of Konstanz, Konstanz, Germany \\ Email: goele.bossaert@ppw.kuleuven.be,nadine.meidert@uni-konstanz.de
}

Received January 21, 2013; revised February 23, 2013; accepted March 3, 2013

Copyright (C) 2013 Goele Bossaert, Nadine Meidert. This is an open access article distributed under the Creative Commons Attribution License, which permits unrestricted use, distribution, and reproduction in any medium, provided the original work is properly cited.

\begin{abstract}
This research studied the concept of enacted peer support during adolescence by means of the Harry Potter Series. A network approach was used. Results indicated the importance of reciprocity and transitivity for enacted peer support during adolescence. Contrary to our expectations, gender, age and personality traits did not affect enacted peer support. No homophily effects based on gender and age were detected. However, students were found to be more supportive of students with similar personality traits. We hope this study adds to the current knowledge on peer support in adolescence and promotes the use of social theories and methods in literacy research.
\end{abstract}

Keywords: Network Dynamics; Peer-to-Peer Networks; Random Graphs

\section{Introduction}

Since in June 1997 the first Harry Potter book was issued, the popularity of the series has steadily increased. According to the New York Times [1], more than 11 million copies of the final book were sold during the first 24 hours in the US, UK, and India alone. For the very few who are not familiar with the story of Harry Potter: Harry is an orphan living with his abusive uncle, aunt and cousin. At age 11, he is recruited by Albus Dumbledore as a wizard for the Hogwarts School of Witchcraft and Wizardry to learn magic. At Hogwarts, he finally finds himself at home, making friends (especially Ronald Weasley and Hermione Granger) and finding people who truly care for him. Throughout his education at Hogwarts, Harry learns more about his family history and his status as "the Chosen one" to defeat the evil wizard Voldemort. With the help of his friends, he faces his archenemy several times throughout the books, until a final confrontation in book 7 .

As can be deducted from the short summary, one of the main topics within the series is peer support, which is also a very well established concept in psychology. Within psychology, social support has been defined in

\footnotetext{
Both authors contributed equally to this article.
}

many ways $[2,3]$. One of the broadest definitions on social support is the one of Tardy [2]. Tardy defines social support as a concept with five dimensions: direction, disposition, description or evaluation, content and network. Direction refers to whether social support is being given or received. Disposition has two dimensions: availability (what support someone has access to, or perceived social support), and enacted (what support someone has used, or received social support). Description or evaluation points to whether an evaluation of the support or a description of the support was given. There are four different types of content in Tardy's model of social support: emotional, instrumental, informational, and/or appraisal. Emotional support refers to support in the form of trust, love, and empathy. Instrumental support consists of resources such as money and time. Informational support refers to provided information or advice on a certain topic. Appraisal support is evaluative feedback to other individuals. The last dimension in this model of social support is network, or the source(s) or the member(s) of an individual's support network.

So far, most researchers have focused on perceived social support, as perceived, and not enacted social support, is the most consistent and compelling indicator of health benefits $[4,5]$. Nonetheless, empirical associations 
between both dimensions of support are quite modest [6]. However, Hobfoll [7] argues that this is an artifact of the manner in which the two variables are measured. Enacted support is often assessed by means of self-report questionnaires with respect to a delimited retrospective period, and often in relation to a particular stressful experience, whereas self-report measures of perceived support allow the respondent to generalize over a wide array of social interactions over long spans of time. Furthermore, it has been argued that the modest associations between enacted social support and mental health outcomes may be in part because it is supportive interactions of which the subject is unaware (i.e., invisible support) that have the most substantial benefits for mental health [8]. In this mind, self-report questionnaires might not be the best way to assess enacted support. Observations of interactions might be a better option to assess enacted support, focusing only on the descriptive dimension of social support in Tardy's model $[9,10]$.

Furthermore, contemporary research examines social support entirely from the perspective of the support recipient, relating perceived social support to gender [11] and personality traits [12] of the support recipient. However, for each recipient of social support, there are one or more support providers, with their own characteristics. Furthermore, social support is likely to be reciprocal [8]. Research on social support with a reciprocal or even more general network perspective (see Tardy's model) is necessary [10]. However, research on social support using these perspectives is still very limited [8].

Finally, research on social support in adolescence has often been cross-sectional. Nonetheless, longitudinal network studies are necessary to study developmental changes in peer support during adolescence [11]. However, so far findings on developmental changes have been contradictory. While most researchers indicate an increase of perceived peer support during adolescence $[10,13]$, others reported that it remains stable [11].

Taking the former knowledge gaps into account, this study aims to add to the literature by focusing on enacted support during adolescence by means of a longitudinal study. The use of observations was recommended in this regard. However, observing students' interactions with their peers in a longitudinal design is a very expensive and time-consuming enterprise.

An answer to this problem might be found in literature, which brings us back to the world of Harry Potter. Researchers in sociology of literature have long argued that texts and stories offer models for interpersonal relations [14]. Therefore, it is proposed to study stories as social facts and to apply social theories to characters and plots in the same way that those theories would be applied to real-life situations. Moreover, we can address gaps of knowledge on certain phenomena that are difficult to assess in real-life situations. The Harry Potter series seems to be particularly lenient for this purpose. Part of the popularity of the series is explained by the fact that these books sketch a context that is very familiar to Western children, touching popular themes and deep psychological issues $[15,16]$. Furthermore, every book narrates the adventures of Harry Potter during one school year at Hogwarts, following Harry and his fellow students from age 11 until age 18. Also, students within Hogwarts are assigned to one of the four houses, according to their personality traits. For example, Gryffindors are brave, while Hufflepuffs main characteristic is loyalty. Ravenclaws are known for their intellect and Slytherins are described as selfish and with a large interest into the Dark Arts.

Hence, based on the Harry Potter series, we would like to generate a better understanding of the development of peer support during adolescence. Therefore, we will focus on enacted support between Harry and his fellow students throughout their stay at Hogwarts. The direction of the enacted peer support will be assessed, by means of a network perspective. This study will mainly focus on the description of several types of peer support. Three general research questions will be addressed.

The first general question addresses the structural changes of peer support during adolescence, i.e., 1) What does the structure of enacted peer support look like during adolescence? More specifically, two questions will be assessed: a) Is peer support reciprocal during adolescence? and b) Is there transitivity in the enactments of peer support (e.g., I support person A and person B, so person A will also support person B)? Based on former research [17], we assume that individuals who have increasingly intimate relationships with each other, also support each other more, and that this support is reciprocal. Consequently, we assume a high rate of reciprocity in peer support during adolescence. Finally, as transitivity is often observed in friendship relations in adolescence, we also assume a positive effect of transitivity on peer support.

A second general question addresses the personal factors that might play a role in the development of peer support, i.e., 2) Which personal factors affect the development of peer support? More specifically, three research questions will be addressed: d) Are girls more involved in peer support networks than boys are? e) Does peer support increase as students grow older? and f) Is there a difference in the enactment of peer support between students with different personality traits? Based on former cross-sectional research on perceived peer support $[11,13]$, we hypothesize that girls will be more involved in peer support networks, as they report more perceived peer support. Based on most former studies on perceived peer support $[10,13]$, we assume that peer 
support increases as children age. As Rowling never mentions students repeating a grade, we can equal age to school year. Hence, we might assume a positive effect of school year on peer support. Furthermore, based on former research relating social support to certain personality traits [12], we expect that students with certain personality traits will be more involved in social support networks than others. Based on the description of the characteristics of the different houses, we might expect that Gryffindors are most supportive, followed by Hufflepuffs, Ravenclaws, and finally Slytherins.

A last general research question focuses on the presence of homophily in the development of peer support during adolescence, i.e., Does homophily affect the development of peer support? Or more specifically; Do students support students who share the same characteristics, i.e., same gender, same age, and same personality traits, more often than they support students who are dissimilar from them? Because adolescents are more likely to engage in social relationships with people who are similar to them (i.e., homophily hypothesis; [18]), they might also be more likely to give support to and receive support from these same peers who they share certain characteristics with, such as gender, age, and personality traits. Support for this hypothesis has long been available in adult women, who have been found to be more likely to provide support, and to both seek and secure support primarily from other women [19]. Therefore, we might expect that students will more often support others who share these same characteristics with them.

\section{Method}

\subsection{Material}

The Harry Potter eBooks were used as basic documents for this study [20-26]. The eBooks were coded in NVivo 9 [21], a computerized qualitative analysis program. Each author coded four books. Book 7 was coded by both authors to assess the inter-rater reliability. Interrater reliability was substantial with Kappa $=0.79$ [22].

\subsection{Participants}

As this study focuses on the development of peer support during adolescence, only students were included in the dataset. The study was limited to the first six books as book 7 mainly concerns issues outside school grounds and peer interactions are limited. In total, 80 students were mentioned in the series. However, since these students were all in different years, we needed to indicate for each book (representing a new school year), which characters were at Hogwarts at the time. For sixteen students, no detailed information regarding the exact time they entered and/or left Hogwarts was provided. Consequently, these sixteen students were deleted from the dataset. Therefore, analyses were based on a total amount of 64 students, 41 boys and 23 girls. Twenty-five students were allocated to the Gryffindor house, 11 students were from Hufflepuff, 13 students belonged to the Ravenclaw house and 15 students were member of the Slytherin house. A large proportion of the students (40.63\%), including Harry Potter, attended Hogwarts as of 1991. The remaining 38 students entered Hogwarts between 1986 and $1995(\mathrm{M}=1990.94 ; \mathrm{SD}=2.09)$. A detailed description of the students included in the analyses is depicted in Table 1.

\subsection{Peer Support}

Contact between the 64 Hogwarts students was coded as peer support when one of the four types of peer support, described in Tardy's model, were found: 1) Student A supports student B emotionally, e.g., in Book 1: Harry, Ron and Hermione assure Neville that he is definitely a Gryffindor when he doubts he is not brave enough to be part of the house; 2) Student A gives students B instrumental help; e.g., in Book 1: Fred and George Weasley help Harry Potter to get his trunk into the compartment of the Hogwarts Express; 3) Student A gives student B certain information to help student B, e.g., in Book 1: Hermione Granger helps Harry Potter with his homework and; 4) Student A praises student B, e.g., in book 5: Terry Boot praises Hermione Granger, for doing a Protean Charm, which is advanced magic.

Furthermore, two extra conditions regarding the context in which peer support appeared needed to be fulfilled as well. First, contact between students was only coded if the peer support was offered voluntarily. Second, only interactions occurring between two living characters, attending Hogwarts at the same moment, were coded as peer support. Consequently, when dead characters reappeared in the books, interactions between these dead characters and living students were not coded. One example for such reappearance is Cedric Diggory's return at the end of book 4, when Cedric asks Harry to return his dead body to his parents. Furthermore, interactions with former or future Hogwarts students at a certain point in time were not included. For example, although Harry and Ginny met before Ginny attended Hogwarts, peer support relations between both characters were only coded when both students attended Hogwarts together.

\subsection{Analysis}

Stochastic actor oriented models (SOAM; [23]) were conducted by means of RSiena to analyze the emergence of support networks in the Harry Potter books. The basic idea of SOAMs is that actors choose their network connections depending on an evaluation of their own position in the network and to obtain a satisfying network 
Table 1. Characters and their attributes.

\begin{tabular}{|c|c|c|c|c|}
\hline \multirow{2}{*}{ Name } & \multicolumn{2}{|c|}{ Gender } & \multirow{2}{*}{ House } & \multirow{2}{*}{ Year } \\
\hline & Boys & Girls & & \\
\hline Adrian Pucey & 1 & & S. & 1989 \\
\hline Alicia Spinnet & & 1 & G. & 1989 \\
\hline Angelina Johnson & & 1 & G. & 1989 \\
\hline Anthony Goldstein & 1 & & $\mathrm{R}$. & 1991 \\
\hline Blaise Zabini & 1 & & $\mathrm{~S}$. & 1991 \\
\hline C. Warrington & 1 & & S. & 1989 \\
\hline Cedric Diggory & 1 & & $\mathrm{H}$. & 1988 \\
\hline Cho Chang & & 1 & $\mathrm{R}$. & 1990 \\
\hline Colin Creevey & 1 & & G. & 1992 \\
\hline Cormac McLaggen & 1 & & G. & 1990 \\
\hline Dean Thomas & 1 & & G. & 1991 \\
\hline Demelza Robins & & 1 & G. & 1993 \\
\hline Dennis Creevey & 1 & & G. & 1994 \\
\hline Draco Malfoy & 1 & & S. & 1991 \\
\hline Eddie Carmichael & 1 & & $\mathrm{R}$. & 1990 \\
\hline Eleanor Branstone & & 1 & $\mathrm{H}$. & 1994 \\
\hline Ernie Macmillan & 1 & & $\mathrm{H}$. & 1991 \\
\hline Euan Abercrombie & 1 & & G. & 1995 \\
\hline Fred Weasley & 1 & & G. & 1989 \\
\hline George Weasley & 1 & & G. & 1989 \\
\hline Ginny Weasley & & 1 & G. & 1992 \\
\hline Graham Pritchard & 1 & & S. & 1994 \\
\hline Gregory Goyle & 1 & & $\mathrm{~S}$. & 1991 \\
\hline Hannah Abbott & & 1 & $\mathrm{H}$. & 1991 \\
\hline Harry James Potter & 1 & & G. & 1991 \\
\hline Hermione Granger & & 1 & G. & 1991 \\
\hline Jimmy Peakes & 1 & & G. & 1994 \\
\hline Justin Finch-Fletchley & 1 & & $\mathrm{H}$. & 1991 \\
\hline Katie Bell & & 1 & G. & 1990 \\
\hline Kevin Whitby & 1 & & $\mathrm{H}$. & 1994 \\
\hline Lavender Brown & & 1 & G. & 1991 \\
\hline Leanne & & 1 & $\mathrm{H}$. & 1991 \\
\hline Lee Jordan & 1 & & G. & 1989 \\
\hline
\end{tabular}

\section{Continued}

\begin{tabular}{|c|c|c|c|c|}
\hline Lucian Bole & 1 & & S. & 1988 \\
\hline Luna Lovegood & & 1 & $\mathrm{R}$. & 1992 \\
\hline Malcolm Baddock & 1 & & S. & 1994 \\
\hline Mandy Brocklehurst & & 1 & R. & 1991 \\
\hline Marcus Belby & 1 & & R. & 1990 \\
\hline Marcus Flint & 1 & & S. & 1986 \\
\hline Michael Corner & 1 & & R. & 1991 \\
\hline Miles Bletchley & 1 & & S. & 1989 \\
\hline Millicent Bulstrode & & 1 & S. & 1991 \\
\hline Natalie McDonald & & 1 & G. & 1994 \\
\hline Neville Longbottom & 1 & & G. & 1991 \\
\hline Oliver Wood & 1 & & G. & 1987 \\
\hline Orla Quirke & & 1 & $\mathrm{R}$. & 1994 \\
\hline Owen Cauldwell & 1 & & H. & 1994 \\
\hline Padma Patil & & 1 & R. & 1991 \\
\hline Pansy Parkinson & & 1 & S. & 1991 \\
\hline Parvati Patil & & 1 & G. & 1991 \\
\hline Penelope Clearwater & & 1 & $\mathrm{R}$. & 1987 \\
\hline Percy Weasley & 1 & & G. & 1987 \\
\hline Peregrine Derrick & 1 & & S. & 1988 \\
\hline Roger Davies & 1 & & $\mathrm{R}$. & 1989 \\
\hline Romilda Vane & & 1 & G. & 1993 \\
\hline Ronald Weasley & 1 & & G. & 1991 \\
\hline Rose Zeller & & 1 & H. & 1995 \\
\hline Seamus Finnigan & 1 & & G. & 1991 \\
\hline Stewart Ackerley & 1 & & $\mathrm{R}$. & 1994 \\
\hline Susan Bones & & 1 & H. & 1991 \\
\hline Terry Boot & 1 & & R. & 1991 \\
\hline Theodore Nott & 1 & & S. & 1991 \\
\hline Vincent Crabbe & 1 & & S. & 1991 \\
\hline Zacharias Smith & 1 & & H. & 1991 \\
\hline \multirow{4}{*}{ Total } & \multirow{4}{*}{41} & \multirow{4}{*}{23} & $25 \mathrm{G}$. & \\
\hline & & & $11 \mathrm{H}$. & \\
\hline & & & $13 \mathrm{R}$. & \\
\hline & & & $15 \mathrm{~S}$. & \\
\hline
\end{tabular}

Note: G. = Gryffindor; H. = Hufflepuff; R. = Ravenclaw; S. = Slytherin 
configuration. A continuous time process is assumed. Therefore, a continuous Markov process taking also the non-observable time periods between the observations into account is used. During this process, actors can withdraw existing ties or create new ties at random moments. However, at any time point the actor can only change one tie $[24,25]$. The actors' preferences for a satisfying network configuration can be expressed by the evaluation function, which can consists of different effects. Three effect categories can be distinguished: 1) Structural effects (e.g., reciprocity) representing network characteristic and their impact on the network formation process; 2) Actor attribute effects which relate to individual characteristics; and 3) Dyadic attribute effects which connect actors among each other [25,26]. In our analysis we included five different forms of effects; three structural effects 1)-3), one attribute effect 4), and one dyadic attribute effect 5).

1) The outdegree (density) effect is defined by the number of outgoing ties [26]. This effect must always be included [26] and is expected to be negative since it controls for the low density in social networks [27].

2) The reciprocity effect is defined by the number of reciprocated ties [26] and is assumed to be positive which means that actors aim to have reciprocated ties.

3) The transitive ties effect is defined by the number of actors to whom a person is directly as well as indirectly tied [26].

4) The covariate ego effect is defined by actors outdegree weighted by his covariate value [26]. This effect captures the impact of individual attributes like gender, school year or house membership on the network formation activity. High parameter values indicate that the covariate increases the likelihood of tie formation.

5) The same covariate effect is defined by the number of ties of one actor to all other actors who have exactly the same value on the covariate [26]. This effect assesses if similar individuals, sharing gender, school year and the same house, are more attracted to each other.

Some extra specifications were needed to suit our data. First, the network composition changed over time since students left and entered Hogwarts at different time points. Consequently, composition change models as suggested by Huisman and Snijders [28] were implemented. This method estimates the network composition of the very time point avoiding the underestimation of the effects. Second, the presence of time heterogeneity, meaning that effects are not constant over time, was to be tested.

\section{Results}

To get a first overview on the network dynamics, we look at the graphical outline of the students' network at
Hogwarts, depicted in Figures 1-3. The position of each actor within the graph is determined by the layout of the aggregated graph [29].

Figure 1 presents the complete network with all 64 students for the first book. In this figure, the overrepresentation of Gryffindor students is obvious. They constitute the center with the main characters Harry Potter, Hermione Granger, and Ron Weasley. Around the Gryffindor students gather most of the Ravenclaws and Hufflepuffs. All Slytherins and some less known Ravenclaws and Hufflepuffs form a circle around this center. Most actors of the circle keep unconnected throughout all books. The only exception is the Slytherin clique around Draco Malfoy. Figures 2 and $\mathbf{3}$ focus on the details of the Harry Potter and Slytherin network and show the dynamic network formation process over time.

Figure 2 focuses on the center with the main characters. Whereas in the first book only the first year students and the Weasleys are connected, the network gets much denser in the second book. On the one hand, the members of the Gryffindor Quidditch team ${ }^{1}$ are now connected with Harry and with themselves, and on the other hand Hufflepuffs, who attend classes together with the Gryffindor students, build up relations with Harry. In the third book even more characters get connected with each other. In book 4, the network density of the support network changes. In book 4, Harry looses a lot of support because he was chosen to participate in the Triwizard Tournament ${ }^{2}$, although younger students like Harry were not allowed to take part in the competition. In contrast, a very dense network can be observed again in book 5 . Obvious is the high connection between Gryffindors, Huffelpuffs, and Ravenclaws indicating the close cooperation between students of all three houses in Dumbledores Army ${ }^{3}$ to fight Lord Voldemort who had returned. The sixth book network again looses in density due to fact that the story gets more and more dedicated to the connections of Harry to the adult characters in the book, like Albus Dumbledore or Severus Snape.

Figure 3 shows the changes within the Slytherin network around Draco Malfoy. There are only a few relationships which can be reported.

Table 2 shows the results of the Stochastic Actor

\footnotetext{
"Quidditch is a wizarding sport played on broomsticks. It is the most popular game among wizards and witches, and, according to Rubeus Hagrid, the equivalent to Muggles' passion for football'. Quote from http://harrypotter.wikia.com/wiki/Quidditch

2"“The Triwizard Tournament is a magical contest held between the three largest wizarding schools of Europe: Hogwarts School of Witchcraft and Wizardry, Durmstrang Institute, and Beauxbatons Academy of Magic, each school being represented by one Champion" Quote from http://harrypotter.wikia.com/wiki/Triwizard_Tournament

3"'Dumbledore's Army, also known as the D.A. or Defense Association, was a secret organization initiated by Harry Potter, Hermione Granger, and Ron Weasley to teach their fellow Hogwarts students proper Defense Against the Dark Arts in 1995." Quote from http://harrypotter.wikia.com/wiki/Dumbledore\%27s_Army
} 


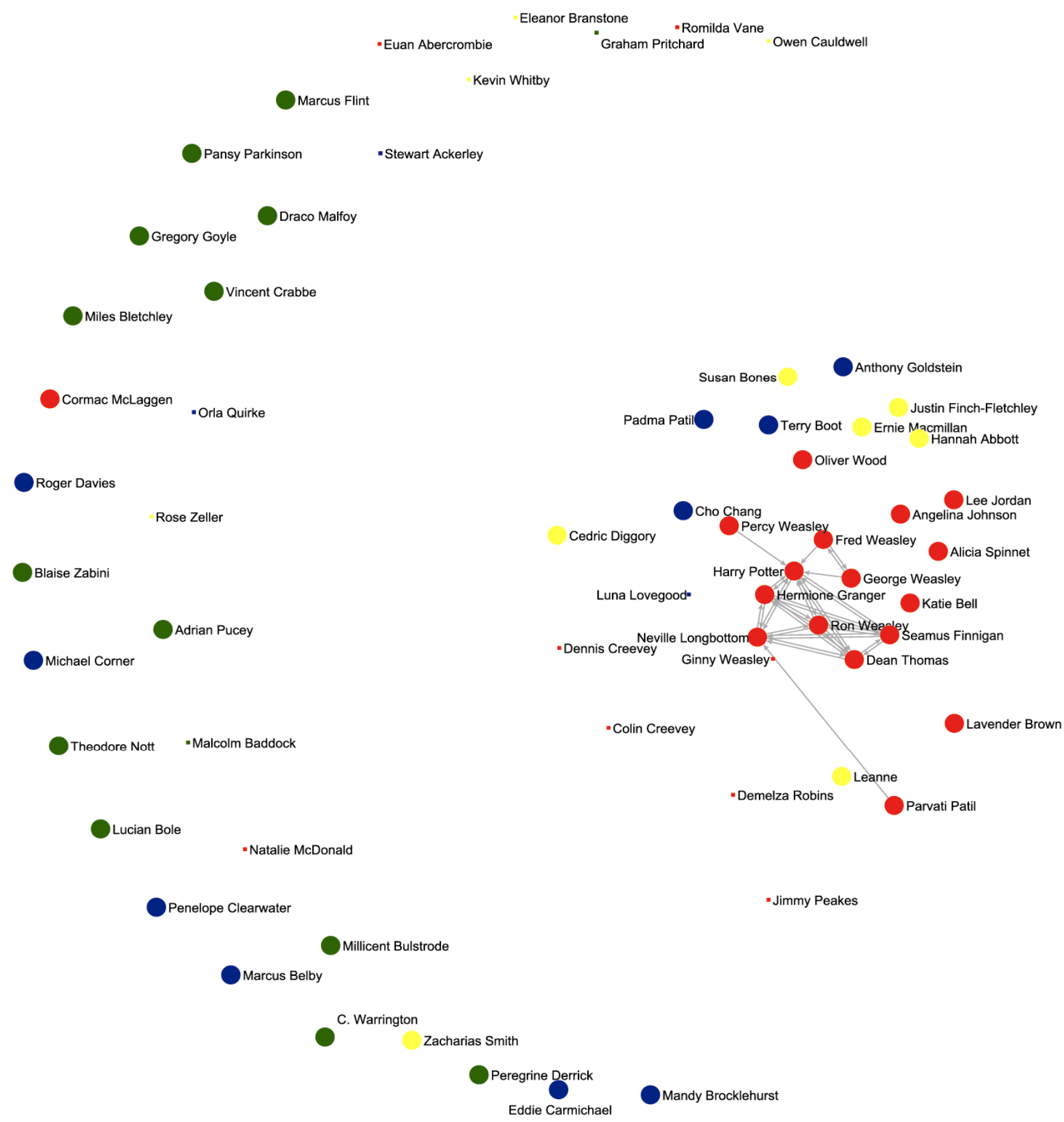

Figure 1. The students' network of Hogwarts for the first book. The circles indicate that the person is attending Hogwarts in the school year 1991-1992, rectangles indicate future students. The colors represent the houses $($ red $=$ Gryffindor, yellow $=$ Hufflepuff, blue $=$ Ravenclaw, green $=$ Slytherin).

Models over all time points (see syntax). Since the score type test proposed by Lospinoso and colleagues [24] indicated time heterogeneity for reciprocity, gender (female), school year, house, and same school year, we included time dummies for all observed periods and interactions between those dummies and the concerned effects. The rows with numbers indicate the interaction between a time dummy and the effect above. For exam- ple, the (3) under reciprocity indicates the interaction effect between the time dummy for the third period and reciprocity.

First, the structural network effects are interpreted. The outdegree effect has the expected significant negative impact on the network controlling for the low density in social networks. The main effect of reciprocity is significant and positive which means that actors tend to 


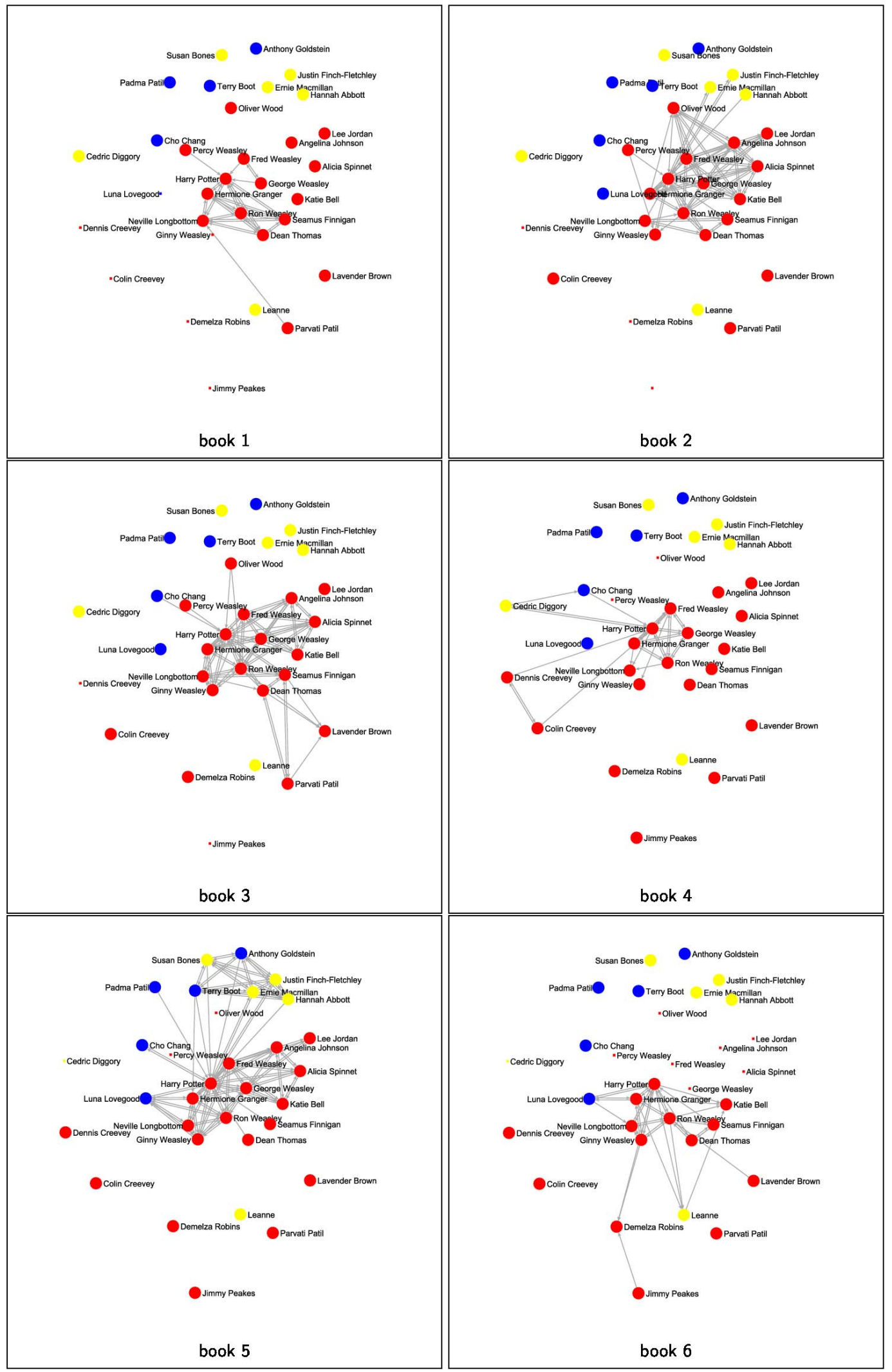

Figure 2. Detail of the students' network of Hogwarts for the first to the sixth book (Harry's network). The circles indicate that the person is attending Hogwarts at the very moment, rectangles indicate future or former students. The colors represent the houses (red = Gryffindor, yellow $=$ Hufflepuff, blue $=$ Ravenclaw). 


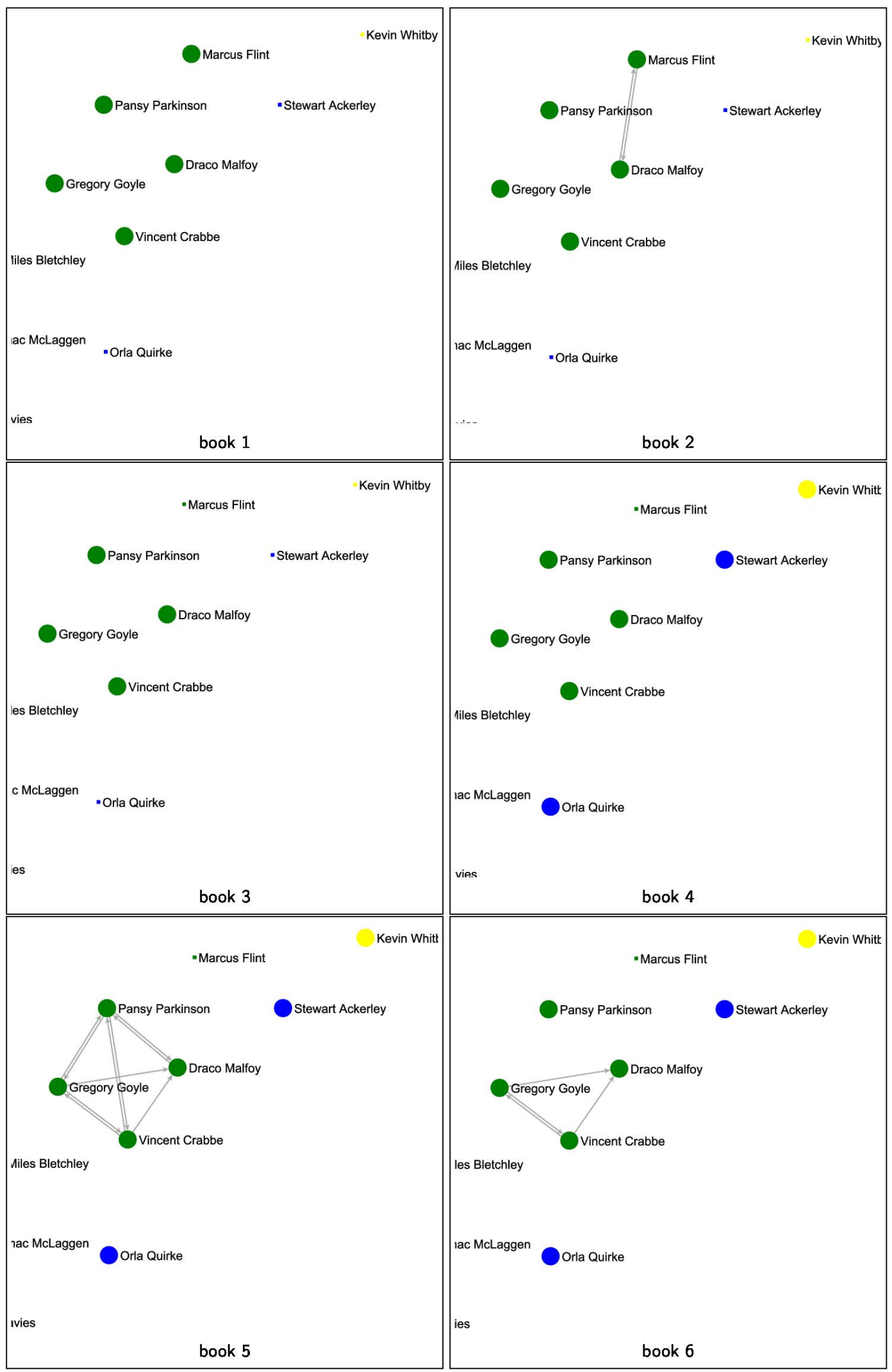

Figure 3. Detail of the students' network of Hogwarts for the first to the sixth book (Slytherin network). The circles indicate that the person is attending Hogwarts at the very moment, rectangles indicate future or former students. The colors represent the houses (green $=$ Slytherin, yellow $=$ Hufflepuff, blue $=$ Ravenclaw). 
Table 2. Results of the stochastic actor models over all time points.

\begin{tabular}{|c|c|c|c|}
\hline & Estimate & Standard error & $\begin{array}{c}\text { Convergence } \\
\text { t-ratio }\end{array}$ \\
\hline Rate parameter (1) & 34.10 & 554.05 & -0.02 \\
\hline Rate parameter (2) & 5.45 & 1.03 & -0.02 \\
\hline Rate parameter (3) & 10.11 & 4.07 & -0.03 \\
\hline Rate parameter (4) & 20.40 & 10.31 & 0.02 \\
\hline Rate parameter (5) & 17.58 & 8.17 & 0.01 \\
\hline Outdegree (density) & -7.10 & 0.49 & 0.00 \\
\hline Reciprocity & 3.36 & 1.16 & 0.00 \\
\hline (2) & -0.71 & 4.41 & -0.01 \\
\hline (3) & -0.02 & 4.00 & 0.00 \\
\hline (4) & 2.81 & 3.73 & 0.03 \\
\hline$(5)$ & -0.40 & 3.61 & -0.02 \\
\hline Transitive ties & 3.77 & 0.57 & 0.00 \\
\hline Gender (female) & -0.21 & 0.27 & 0.01 \\
\hline (2) & 0.11 & 1.55 & -0.02 \\
\hline (3) & -2.86 & 1.79 & 0.01 \\
\hline (4) & 0.04 & 1.58 & 0.02 \\
\hline (5) & -0.90 & 1.55 & -0.04 \\
\hline School year & 0.04 & 0.41 & 0.03 \\
\hline (2) & 0.87 & 2.01 & -0.03 \\
\hline (3) & 0.66 & 1.93 & -0.01 \\
\hline (4) & 0.36 & 2.01 & 0.01 \\
\hline (5) & 0.88 & 2.06 & -0.02 \\
\hline House $^{a}$ & -0.35 & 0.58 & 0.03 \\
\hline (2) & -0.50 & 1.20 & -0.01 \\
\hline (3) & 0.31 & 1.30 & -0.05 \\
\hline (4) & 0.41 & 1.59 & -0.01 \\
\hline (5) & 0.08 & 1.44 & 0.01 \\
\hline Same gender & -0.02 & 0.59 & 0.01 \\
\hline Same school year & 0.44 & 0.40 & 0.02 \\
\hline (2) & 0.11 & 2.37 & -0.02 \\
\hline (3) & -2.22 & 2.75 & -0.01 \\
\hline (4) & 0.79 & 2.15 & 0.03 \\
\hline (5) & -0.28 & 2.56 & -0.04 \\
\hline Same house & 1.03 & 0.33 & 0.02 \\
\hline Time dummy 2 & & fixed & \\
\hline Time dummy 3 & & fixed & \\
\hline Time dummy 4 & & fixed & \\
\hline Time dummy 5 & & fixed & \\
\hline
\end{tabular}

return support they receive in the first period. The interactions between the time dummies and reciprocity are all negative except the interaction with the time dummy for the fourth period that is strongly positive. However, none of these interaction terms are significant. The effect of transitive ties is strongly positive and significant.

Secondly, the covariate ego effects are interpreted to check which attributes of the actor who support others determine the network formation process. Gender has a negative, but non-significant effect on network formation. Moreover, all interaction terms are non-significant. The main effect of school year, which is the effect of school year in the first period, is positive but quite small and non-significant. Also the interaction terms are non-significant. The main house effect is as expected negative but non-significant. Since Gryffindors are described to be brave and Slytherins as selfish, a negative impact on the support willingness was assumed. Also the interaction terms are non-significant.

Finally, the same covariate effects are interpreted. Having the same gender does not have a significant positive impact on the network formation. Same school year has in the first period a positive, but non-significant effect. Over time, this effect changes, decreases and increases in some periods. Nevertheless, being in the same school year does not have the expected positive effect on support relations between two students. Finally, the same house effect has a strong significant effect on the support network and proves to be a relevant context variable.

\section{Discussion}

\subsection{Summary}

The general aim of this study was to generate a better understanding of the development of peer support during adolescence, based on the enacted peer support in the Harry Potter series. More specifically, three general questions were addressed, i.e., 1) What are the structural characteristics in peer support during adolescence? 2) Which personal factors affect the enactment of peer support? and 3) Does homophily affect the enactment of peer support? Based on former research, several hypotheses were formulated.

Two structural characteristics, i.e., reciprocity and transitivity were assessed. It was hypothesized that peer support would be reciprocal during adolescence. Our results confirm this thesis. Since time heterogeneity was detected, dummy scores for each time change had to be included in the analysis. During the first time change (from book 1 to book 2), a significant and positive effect was found for reciprocity, meaning that reciprocity of peer support relations indeed increased between the first and the second book. However, in the following books, reciprocity decreased but the main effect remained posi- 
tive. Our second hypothesis stated that transitivity was another important characteristic of peer support. Results of the final analysis confirmed this thesis, so that we can conclude that if a student supports student A and student $\mathrm{B}$, chances are high that student A will also support student B.

A second general question addressed the effect of personal factors on the development of peer support. In this study, we focused on three main characteristics, i.e., gender, age and personality traits. Contrary to former studies on perceived support, no significant effects of gender, age, and personality traits were found on the development of enacted peer support. Although these findings do not correspond with our expectations, these differences do confirm that there might be a significant difference between the perception of respondents and the actual interactions, or enacted peer support $[6,9,10]$.

A last question focused on the effect of homophily on the development of peer support, stating that students prefer to interact with similar peers [18]. Our results confirm this hypothesis only partially. Although being of the same gender and same age did not seem to affect the level of peer support of students, sharing personality characteristics did affect peer support among students. However, several notes can be made regarding these findings. First of all, contrary to many real-life contexts, the proportion girls-boys within the books is not equally divided. The majority of the students at Hogwarts are boys. Therefore, chances increase that girls choose for mixed relations. Second, Hogwarts is a boarding school, situated in an isolated area. Consequently, students of all ages also spent all their spare time together. For example, students of different ages are part of the same Quidditch team, thus increasing chances to interact with students from different ages. Finally, we did find that students sharing the same personality traits do significantly more often support each other. It can be concluded that the results of this study did confirm that students do tend to support students who resemble them in a certain way, gender and age notwithstanding.

\subsection{Strengths, Limitations and Future Directions}

This study contributes to our understanding of the development of social support during adolescence. Several strengths of this study, for different disciplines, can be pointed out. First of all, this study is one of the rare studies on enacted peer support. Secondly, it is among the rare longitudinal studies on the development of peer support during adolescence. Third, it is the first study with a network perspective on peer support among adolescents. Although these findings might only be based on a fictional story, its results have indicated the importance of structural and homophily effects on the development of peer support during adolescence. Finally, this study is among the first to use fictional stories in research on social support, and to combine it with longitudinal social network analysis. To our knowledge, only one other study reported on the network dynamics in a fictional story and checked whether similarities within the structure of the networks could be found to real social networks [30]. However, the relevance of this study remained limited to literacy research, whereas this study strives to add to the current literature in psychology. However, as claimed by De Nooy [14], studying fictional stories can help us gain insight in reality. We hope many studies will follow.

Some limitations should be pointed out as well. First of all, this study focused on only one aspect of peer support, i.e., enacted peer support. However, as the results of this study underline, to get a complete overview of the development of social support during adolescence, both dimensions of support, i.e., perceived and enacted peer support should be taken into account.

A second limitation of this study is related to the method being used. As was proposed by De Nooy [14], this study made use of a fictional story to address the development of enacted peer support during adolescence. Nonetheless, studying social theories based on stories also has its disadvantages. For example, the data for the study completely depended on what J. K. Rowling showed us of the world of Harry Potter. The story focuses on the life of Harry and his friends, and a lot less is known of the interactions of the side characters. Therefore, real observations in network perspective, with multiple observers for simultaneous observations, would possibly generate a much broader and detailed view on the development of peer support. However, this often remains an ideal situation, a utopia for which we all strive.

Related to this remark, when working with fictional stories, you have to use the available indicators of the concepts you want to assess. For example, during the analysis, we used the variable "house" as an indicator of personality traits. However, it might as well be argued that "house" says more about the context in which the students strive (for example, students who are in the same house, are also in the same classes, and also share bedrooms and common rooms together), than about their actual personality traits. Furthermore, the allocation of students to particular houses is only a rough categorization of these students according to their main personality trait (i.e., brevity, loyalty, intelligence, selfishness and interest in the Dark Arts), ignoring possible dimensional differences on these traits between students. Finally, this categorization does not take possibly more relevant, personality traits for enacted peer support into account.

A third limitation of this study concerns the quality of the results. The necessity to include time dummies to 
control for time heterogeneity might also be a sign of a poorly fitting model. With the score type test [31], we tested if other structural effects like indegree popularity or activity should be included. However, the tests results indicated that no further improvement would be achieved adding these effects.

The results of this study also generated some interesting new questions and recommendations for future research on the development of social support in adolescence.

The most important question is whether similar findings, i.e., the effect of reciprocity, transitivity and the homophily effect of personal traits on the development of enacted support would also be found in real-life situations. It might also be interesting to compare the outcomes based on the books of Harry Potter to the outcomes based on observations of adolescents in real-life, to evaluate the use of social stories, and more specifically, the books of J. K. Rowling, as a source to test social theories.

Furthermore, following the premises of Cauce and colleagues [9], Furman and Buhrmeister [10] and Hobfoll [7], multi-method research is needed in order to get a thorough understanding of the development of social support during adolescence and its effects on mental health in adulthood. Only by means of complementary methods one can be sure to thoroughly grasp social support, without excluding the "invisible support".

\section{Acknowledgements}

The work reported in this paper is part of a project funded by the European Science Foundation (ESF) for the activity entitled "Quantitative Methods in the Social Sciences".

We are grateful to Daniela Kromrey who had the idea for the project saying in good fun the Harry Potter networks might be interesting to analyze. She was absolutely right.

\section{REFERENCES}

[1] The New York Times, "Harry Potter Tale Is the FastestSelling Book in History," 2007.

http://www.nytimes.com/2007/07/23/business/worldbusin ess/23iht-potter.4.6789605.html

[2] C. Tardy, "Social Support Measurement," American Journal of Community Psychology, Vol. 13, No. 2, 1985, pp. 187-202. doi:10.1007/BF00905728

[3] T. A. Wills and O. Shinar, "Measuring Perceived and Received Social Support," In: S. Cohen, L. G. Underwood and B. H. Gottlieb, Eds., Social Support Measurement and Intervention: A Guide for Health and Social Scientists, Oxford University Press, Oxford, 2000, pp. 86135.

[4] V. S. Helgeson, "Two Important Distinctions in Social
Support: Kind of Support and Perceived versus Received," Journal of Applied Social Psychology, Vol. 23, No. 10, 1993, pp. 825-845. doi:10.1111/j.1559-1816.1993.tb01008.x

[5] E. Wethingthon and R. C. Kessler, "Perceived Support, Received Support and Adjustment to Stressful Life Events," Journal of Health and Social Behavior, Vol. 27, No. 1, 1986, pp. 78-89. doi:10.2307/2136504

[6] B. Lakey, E. Orehek, K. L. Hain and M. vanVleet, "Enacted Support's Links to Negative Affect and Perceived Support Are More Consistent with Theory When Social Influences Are Isolated from Trait Influences," Personality and Social Psychology Bulletin, Vol. 36, No. 1, 2010, pp. 132-142. doi:10.1177/0146167209349375

[7] S. E. Hobfoll, "Social Support: The Movie," Journal of Social and Personal Relationships, Vol. 26, No. 1, 2009, pp. 93-101. doi:10.1177/0265407509105524

[8] J. B. Turner and R. J. Turner, "Social Relations, Social Integration, and Social Support," In: C. S. Aneshensel, J. C. Phelan, J. C. and A. Bierman, Eds., Handbook of the Sociology of Mental Health, Springer, Dordrecht, 2013, pp. 341-356.

[9] M. Cauce, C. Mason, N. Gonzales, Y. Hiraga and G. Liu, "Social Support during Adolescence: Methodologi- cal and Theoretical Considerations," In: F. Nestmann and K. Hurrelmann, Eds., Social Networks and Social Support in Childhood and Adolescence, de Gruyter, Berlin, 1994, pp. 89-108. doi:10.1515/9783110866377.89

[10] W. Furman and D. Buhrmeister, "Age and Sex Differences in Perception of Networks of Personal Relationships," Child Development, Vol. 63, No. 1, 1992, pp. 103115. doi:10.2307/1130905

[11] C. L. Bokhorst, S. R. Sumter and P. M. Westenberg, "Social Support from Parents, Friends, Classmates, and Teachers in Children and Adolescents Aged 9 to 18 Years: Who Is Perceived as Most Supportive?" Social Development, Vol. 19, No. 2, 2010, pp. 417-426. doi:10.1111/j.1467-9507.2009.00540.x

[12] L.-X. Xia, J. Liu, C. Ding, S. D. Hollon, B. T. Shao and Q. Zhang, "The Relation of Self-Supporting Personality, Enacted Social Support, and Perceived Social Support," Personality and Individual Differences, Vol. 52, No. 2, 2012, pp. 156-160. doi:10.1016/j.paid.2011.10.002

[13] M. Helsen, W. Vollebergh and W. Meeus, "Social Support from Parents and Friends and Emotional Problems in Adolescence," Journal of Youth and Adolescence, Vol. 29, No. 3, 2000, pp. 319-335. doi:10.1023/A:1005147708827

[14] W. De Nooy, "Stories and Social Structure: A Structural Perspective on Literature in Society," In: D. Schram and G. Steen, Eds., The Psychology and Sociology of Literature: In Honor of Elrud Ibsch, John Benjamins Publishing, Co., Amsterdam, 2001, pp. 359-375.

[15] M. W. Bukowski, "Friendship and the Worlds of Childhood," In: D. W. Nangle and C. A. Erdley, Eds., The Role of Friendship in Psychological Adjustment. New Directions for Child and Adolescent Development, Jossey-Bass, San Francisco, Vol. 91, 2001, pp. 93-106.

[16] J. Rosegrant, "The Deathly Hallows: Harry Potter and Adolescent Development," Journal of Psychoanalytic As- 
sociation, Vol. 57, No. 6, 2009, pp. 1401-1423. doi:10.1177/0003065109352491

[17] K. H. Rubin, W. Bukowski and J. G. Parker, "Peer Interactions, Relationships and Groups," In: N. Eisenberg, Ed., Social, Emotional and Personal Development, 6th Edition, John Wiley \& Sons, Inc., Wiley, 2006, pp. 571-645.

[18] M. McPherson, L. Smith-Lovin and J. M. Cook, "Birds of a Feather: Homophily in Social Networks," Annual Review of Sociology, Vol. 27, 2001, pp. 415-444. doi:10.1146/annurev.soc.27.1.415

[19] D. Belle, "The Stress of Caring: Women as Providers of Social Support," In: L. Goldberger and S. Breznitz, Eds., Handbook of Stress: Theoretical and Clinical Aspects, Free Press, New York, 1982, pp. 496-505.

[20] J. K. Rowling, "The Complete Harry Potter CollectioneBook," Bloomsbury Children's Books, London, 2012. http://shop.pottermore.com/en_GB/The-Complete-HarryPot-ter-Collection-ebook/hpbundle1-7-ebook-english-gb1 - gbp? $=$ GBP

[21] QSR International, NVivo 7 [Computer software], 2006. http://www.qsrinternational.com/products_previous-prod ucts_nvivo7.aspx

[22] J. Viera and J. M. Garrett, "Understanding Interobserver Agreement: The Kappa statistic," Family Medicine, Vol. 37, No. 5, 2005, pp. 360-363.

[23] T. A. B. Snijders, "The Statistical Evaluation of Social Network Dynamics," In: M. E. Sobel and M. P. Becker, Eds., Sociological Methodology, Basil Blackwell, London, Vol. 31, 2001, pp. 361-195.

[24] J. Lospinoso, M. Schweinberger, T. Snijders and R. Ripley, "Assessing and Accounting for Time Heterogeneity in Stochastic Actor Oriented Models," Advances in Data
Analysis and Classification, Vol. 5, No. 2, 2011, pp. 147176. doi:10.1007/s11634-010-0076-1

[25] M. A. J. van Duijn, E. P. H. Zeggelink, M. Huisman, F. N. Stokman and F. W. Wasseur, "Evolution of Sociology Freshmen into a Friendship Network," Journal of Mathematical Sociology, Vol. 27, No. 2-3, 2003, pp. 153-191. doi: $10.1080 / 00222500305889$

[26] R. M. Ripley, T. A. B. Snijders and P. Preciado, "Manual for RSiena September 22, 2012," University of Oxford, Oxford, 2012.

[27] C. E. G. Steglich, T. A. B. Snijders and M. A. Pearson, "Dynamic Networks and Behavior: Separating Selection from Influence," Sociological Methodology, Vol. 40, No. 1, 2010, pp. 329-393. doi:10.1111/j.1467-9531.2010.01225.x

[28] M. E. Huisman and T. A. B. Snijders, "Statistical Analysis of Longitudinal Network Data with Changing Composition," Sociological Methods and Research, Vol. 32, No. 2, 2003, pp. 253-287. doi:10.1177/0049124103256096

[29] U. Brandes, N. Indlekofer and M. Mader, "Visualization Methods for Longitudinal Social Networks and Stochastic Actor-Oriented Modeling," Social Networks, Vol. 34, No. 3, 2012, pp. 291-308. doi:10.1016/j.socnet.2011.06.002

[30] P. M. Gleiser, "How to Become a Superhero," Journal of Statistical Mechanics: Theory and Experiment, 2007, Article ID: P09020. http://iopscience.iop.org/1742-5468/2007/09/P09020

[31] M. Schweinberger, "Statistical Modelling of Network Panel Data: Goodness of Fit," British Journal of Mathematical and Statistical Psychology, Vol. 65, No. 2, 2012, pp. 263-281. doi:10.1111/j.2044-8317.2011.02022.X 